\title{
AN ANALYSIS OF WIRE-CUT PARAMETERS IN ELECTRIC-DISCHARGE OF TITANIUM ALLOYS
}

\author{
FAROOK NEHADABED ${ }^{1}$, AZWAN BIN SAPIT ${ }^{2} \&$ SAAD KARIEMSHATHER $^{\mathbf{3}}$ \\ ${ }^{1,2}$ Faculty of Mechanical, Manufacturing Engineering, Universiti Tun Hussein Onn Malaysia, Iraq \\ ${ }^{3}$ Production Engineering, University of Technology, Iraq
}

\begin{abstract}
The present paper, focuses on wire electric dis-charge machine of titanium alloys. It can be considered as an attempt to develop two models of response variables, they are; the operating rate, the surface-roughness, and the rate of material removing, In the wire electric dis-charge machine process using the response surface methodology. The pilot plan is based on Minitab 18, and the analysis convey the major six parameters. ANOVA was applied to determine the importance of the advanced model, the test results confirm the validity and suitability of the advanced RSM-model. Lastly, the optimum parameter settings is improved.
\end{abstract}

KEYWORDS: Wire Electric Dis-Charge Machine, Titanium \& MR, SR \& RSM

Received: Jun 01, 2019; Accepted: Jun 20, 2019; Published: Oct 26, 2019; Paper Id.: IJMPERDAUG2019141

\section{INTRODUCTION}

There are various materials from complex disciplines in the field of engineering branches, especially mechanical engineering where the path of mechanical engineering study includes the characteristics of materials of various types, especially those that contain high hardness and excellent strength and resistance to the impact of weight and light weight and excellent resistance to corrosion and much more. The deep study for such materials, requires care attention. Examples for such materials are, composites of alloy-ceramic, alloy-materials and/or hard-materials such as Tungsten-Carbide, Titanium, etc., all have evolved to meet the daily life demands. One of the most important material used in mechanical engineering is the Titanium due to its highest-strength regarding to the weighted ratio compared to all other metals. Due to the hardness of titanium compared to other materials, the feeding rate of the milling machine will have a thickness of about half the thickness of the feeding rate, which makes it difficult to operate the machine during preparation in comparison with aluminum or steel. Another reason is that the tool which cuts them generates much more heat than aluminum or steel when compared with titanium. This heat will also work on the heat treatment of titanium making it more difficult than the carbide cutting tools, thus breaking the tool. We would like to point out that in its solid state, titanium hardness will be similar to stainless steel, and all these reasons provide a platform for the current research to use titanium as a material that can be manufactured by the process of cutting vacuum wire. Kumar, Kumar, Kumar [1] focuses on the process of manufacturing of electrical wires. In this research, the researchers show an intensive study on the research the process of cutting off vacuum wiring, which includes improving process parameters that investigate the effect of various factors affecting the performance and productivity of machines. Selvakumar, Jiju, Brazil, Sarkar and Mitra [2-3] have the main objective of selecting the best combination of mechanical treatment for the manufacture of titanium wires. Prasad Arikatla, Tamil Mannan and Krishnaya[4-6] investigated the low effect of machine parameters on the cutting speed and rate of removal of materials for the manufacture of Nimonic 80A with 
copper wire as a tool pole during the process of manufacturing electrical discharge by wire. The statistical analysis and regression of the slit width was proposed using the design of experiments by Parashar, Rehman, Bhagoria, and Puri[7] in their research work. Quadratic mathematical models were derived to represent the behavior of the process in electrical wiring. Operation of machines by Datta \& Mahapatra, ND [8-9] and make the modern gradient of newer and more difficult material processing task in WEDM very difficult, so as to optimize the use of all resources. The present paper, focuses on wire electric dis-charge machine of titanium alloys. It can be considered as an attempt to develop two models of response variables, they are; the operating rate, the surface-roughness, and the rate of material removing, in the wire electric discharge machine process using the response surface methodology. The pilot plan is based on Minitab 18, and the analysis convey the major six parameters. A NOVA was applied to determine the importance of the advanced model, the test results confirm the validity and suitability of the advanced RSM-model. Lastly, the optimum parameter settings is improved.

\section{PROPOSED EXPERIMENT SETTINGS}

The current experiment is a pilot study where MRR and SR are being studied to evaluate the performance of the MRR, SR and Over Cut machines with input configurations such as:

- Feed rate wire,

- Wire tension,

- Pulse on time,

- $\quad$ Pulse stop time,

- Current voltage for peak and voltage range.

Electromagnetic Sprint cut-734 has been tested on the EDM system. Figure (1) illustrates the experimental setup used with the EDM CNC machine. The electrode wire was used in copper plated with $0.25 \mathrm{~mm}$ diameter and the deionized water was sterilized as the insulating fluid around the wire and lateral cleaning technique. We would like to point out that the previous indicators are in Table (1).

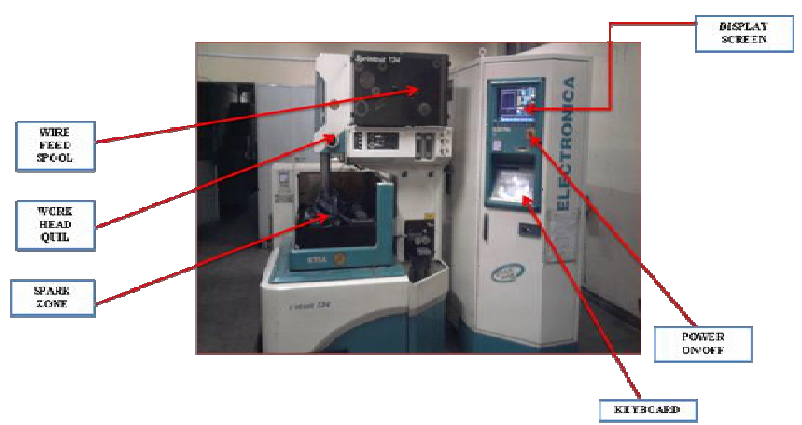

Figure 1: Four-Axis Electronic A Sprint Cut-734 CNC WEDM.

Table 1: Parameters and their Range

\begin{tabular}{|cl|l|c|}
\hline Number & \multicolumn{1}{c|}{ Parameter } & \multicolumn{2}{c|}{ Specific Details } \\
\hline 1 & On-time pulse & TON & $105-130 \mathrm{mu}$ \\
\hline 2 & Off-time pulse & TOFF & $36-60 \mathrm{mu}$ \\
\hline 3 & Peak-current & IP & $40-230 \mathrm{~A}$ \\
\hline 4 & Spark-gap-set-voltage & SGSV & $5-75 \mathrm{~V}$ \\
\hline 5 & Rate ofwire-feed & RWF & $2-12 \mathrm{~m} / \mathrm{min}$ \\
\hline 6 & Tension of wire & TW & $2-12 \mathrm{mu}$ \\
\hline
\end{tabular}


Table 2: Chemical Compositions of Titanium Alloy (Ti-6242)

\begin{tabular}{|l|l|l|l|l|l|l|l|l|l|l|l|}
\hline Elements & $\mathrm{Al}$ & $\mathrm{Sn}$ & $\mathrm{Zr}$ & $\mathrm{Mo}$ & $\mathrm{Si}$ & $\mathrm{Fe}$ & $\mathrm{O} 2$ & $\mathrm{C}$ & $\mathrm{N} 2$ & $\mathrm{H} 2$ & $\mathrm{Ti}$ \\
\hline $\begin{array}{l}\text { \% Maximum } \\
\text { wt }\end{array}$ & 6.0 & 2.0 & 4.0 & 2.0 & 0.13 & 0.25 & 0.15 & 0.08 & 0.05 & 0.0125 & 85.3 \\
\hline
\end{tabular}

\section{ANALYSIS OF NUMERICAL COMPUTATIONS}

Table (3) shows the measured-values for MRR\&SR responses, respectively, corresponds to BBD-design-matrix, also effects of process-parameters on MRR \& SR had-been analysed by the response-surface and contour-plots.

Table 3: Design Matrix and Output Responses

\begin{tabular}{|c|c|c|c|c|c|c|c|c|}
\hline Run Number & $\begin{array}{l}\text { On-Time } \\
\text { pulse }\end{array}$ & $\begin{array}{l}\text { Off-Time } \\
\text { Pulse }\end{array}$ & $\begin{array}{l}\text { Peak- } \\
\text { Current }\end{array}$ & $\begin{array}{l}\text { Spark-gap- } \\
\text { Voltage }\end{array}$ & Rate of Wire-Feed & $\begin{array}{l}\text { Tension of } \\
\text { Wire }\end{array}$ & 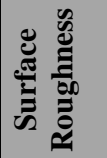 & 晃 \\
\hline 1 & 1.1 & 28 & 200 & 50 & 7 & 500 & 3.22 & 9.6 \\
\hline 2 & 0.9 & 38 & 160 & 50 & 4 & 500 & 2.48 & 4.92 \\
\hline 3 & 0.7 & 28 & 160 & 60 & 4 & 950 & 2.23 & 3.39 \\
\hline 4 & 0.9 & 17 & 120 & 50 & 10 & 950 & 2.75 & 8.29 \\
\hline 5 & 0.9 & 28 & 120 & 60 & 7 & 500 & 2.47 & 4.45 \\
\hline 6 & 1.1 & 28 & 160 & 40 & 4 & 950 & 2.93 & 9.2 \\
\hline 7 & 0.9 & 38 & 160 & 50 & 10 & 1400 & 2.48 & 4.77 \\
\hline 8 & 0.9 & 28 & 160 & 50 & 7 & 950 & 2.65 & 5.19 \\
\hline 9 & 0.9 & 17 & 160 & 50 & 4 & 500 & 2.81 & 8.81 \\
\hline 10 & 1.1 & 28 & 160 & 40 & 10 & 950 & 2.94 & 8.59 \\
\hline 11 & 1.1 & 38 & 160 & 40 & 7 & 950 & 2.91 & 8.3 \\
\hline 12 & 1.1 & 28 & 160 & 60 & 4 & 950 & 2.83 & 7.03 \\
\hline 13 & 0.9 & 17 & 160 & 50 & 10 & 500 & 2.79 & 8.19 \\
\hline 14 & 0.9 & 28 & 160 & 50 & 7 & 950 & 2.61 & \begin{tabular}{|l|}
4.67 \\
\end{tabular} \\
\hline 15 & 0.7 & 28 & 120 & 50 & 7 & 500 & 2.49 & 3.28 \\
\hline 16 & 0.9 & 28 & 160 & 50 & 7 & 950 & 2.68 & 5.51 \\
\hline 17 & 0.9 & 28 & 120 & 60 & 7 & 1400 & 2.49 & 4.66 \\
\hline 18 & 0.7 & 38 & 160 & 40 & 7 & 950 & 2.32 & 3.65 \\
\hline 19 & 0.9 & 38 & 120 & 50 & 10 & 950 & 2.31 & 4.37 \\
\hline 20 & 0.9 & 28 & 200 & 40 & 7 & 1400 & 2.89 & 6.72 \\
\hline 21 & 0.9 & 28 & 200 & 60 & 7 & 500 & 2.69 & 6.67 \\
\hline 22 & 0.9 & 38 & 200 & 50 & 10 & 950 & 2.57 & 6.54 \\
\hline 23 & 0.9 & 28 & 120 & 40 & 7 & 1400 & 2.71 & 5.07 \\
\hline 24 & 0.7 & 28 & 120 & 50 & 7 & 1400 & 2.51 & 3.3 \\
\hline 25 & 0.9 & 38 & 200 & 50 & 4 & 950 & 2.56 & 7.07 \\
\hline 26 & 1.1 & 28 & 160 & 60 & 10 & 950 & 2.82 & 6.77 \\
\hline 27 & 1.1 & 28 & 120 & 50 & 7 & 500 & 2.77 & 7.1 \\
\hline 28 & 0.7 & 28 & 160 & 40 & 10 & 950 & 2.35 & 4.27 \\
\hline 29 & 0.7 & 28 & 200 & 50 & 7 & 500 & 2.48 & \begin{tabular}{|l|}
4.49 \\
\end{tabular} \\
\hline 30 & 0.7 & 17 & 160 & 40 & 7 & 950 & 2.70 & 6.9 \\
\hline 31 & 0.7 & 28 & 200 & 50 & 7 & 1400 & 2.51 & 4.44 \\
\hline 32 & 0.9 & 28 & 160 & 50 & 7 & 950 & 2.65 & 4.7 \\
\hline 33 & 0.9 & 17 & 200 & 50 & 4 & 950 & 2.88 & 8.06 \\
\hline 34 & 0.9 & 28 & 160 & 50 & 7 & 950 & 2.65 & 5.61 \\
\hline 35 & 1.1 & 17 & 160 & 40 & 7 & 950 & 3.28 & 11.16 \\
\hline 36 & 0.9 & 17 & 200 & 50 & 10 & 950 & 2.98 & 8.28 \\
\hline 37 & 0.9 & 28 & 200 & 40 & 7 & 500 & 2.84 & 7.07 \\
\hline 38 & 0.7 & 28 & 160 & 40 & 4 & 950 & 2.33 & 4.41 \\
\hline 39 & 0.9 & 38 & 160 & 50 & 10 & 500 & 2.50 & 4.96 \\
\hline 40 & 0.9 & 28 & 160 & 50 & 7 & 950 & 2.69 & 5.65 \\
\hline 41 & 1.1 & 38 & 160 & 60 & 7 & 950 & 2.66 & 6.77 \\
\hline
\end{tabular}




\begin{tabular}{|c|c|c|c|c|c|c|c|c|}
\hline 42 & 0.7 & 17 & 160 & 60 & 7 & 950 & 2.60 & 4.14 \\
\hline 43 & 0.9 & 28 & 200 & 60 & 7 & 1400 & 2.68 & 6.57 \\
\hline 44 & 0.9 & 17 & 120 & 50 & 4 & 950 & 2.75 & 7.61 \\
\hline 45 & 0.7 & 28 & 160 & 60 & 10 & 950 & 2.28 & 3.75 \\
\hline 46 & 1.1 & 28 & 120 & 50 & 7 & 1400 & 2.75 & 7.11 \\
\hline 47 & 0.7 & 38 & 160 & 60 & 7 & 950 & 2.15 & 3.28 \\
\hline 48 & 0.9 & 17 & 160 & 50 & 4 & 1400 & 2.85 & 8.15 \\
\hline 49 & 0.9 & 28 & 120 & 40 & 7 & 500 & 2.78 & 5.36 \\
\hline 50 & 1.1 & 17 & 160 & 60 & 7 & 950 & 3.00 & 8.45 \\
\hline 51 & 0.9 & 38 & 120 & 50 & 4 & 950 & 2.29 & 4.55 \\
\hline 52 & 1.1 & 28 & 200 & 50 & 7 & 1400 & 3.12 & 8.37 \\
\hline 53 & 0.9 & 17 & 160 & 50 & 10 & 1400 & 2.82 & 7.53 \\
\hline 54 & 0.9 & 38 & 160 & 50 & 4 & 1400 & 2.49 & 4.92 \\
\hline
\end{tabular}

\section{MATERIAL REMOVAL RATE ANALYSIS}

In the present paper, the MRR-Quadratic-Model was developed using Mini-tab 18, the ability of the model had been produced using ANOVA and tested at level of confidence - 95\%, the results are given in table (4), as it is clear from table (4), one can prove that the F-value is 97.91 and the P-corresponding value $<0.0001$, therefore, the squared-form is high at the level 95\%, also, one can note that $\mathrm{P}$ will not be appropriate for the value $>0.05$ ( greater than 0.05 ), therefore, the deficiency of fitness is not-important, also, the deficiency of the fit-value of 0.475 has the meaning, it is not important for pure-error. In addition, the value of $R_{2}$ is 0.9457 and shows $94.57 \%$ of the change in the MRR rate, due to the control-factors. Add to the previous result the expectation of $R_{2}$ at 0.9228 is acceptable compared with $R_{2} 0.9360$ that gives a high-correlation among the observed-values. Referring to Figure (2.1), which shows the normal-probability of MRR residues, also, it shows that errors are usually distributed. The observed-value for scheme are in figures (2.2-2.4), and they give the fact that the observed-response is very closer to the expected-values, and the model can determine the actual relation between process-parameters and outputs. From the computations one can conclude that the appropriate-resolution is 40.903 and this is suggests using a quadratic-model for navigation of R-design area. From the computation and analysis, one also conclude that the values of F and P that the factors A (TON) and B (TOFF) are the most important for MRR. The analysis leads to the fact that it can also be seen from the \% age values of the input resulted for each source, determine how much of the parameter contributes to MRR.

\section{Material Removal Rate}

$\mathrm{MRR}=22.086+10.2396 \times \mathrm{TON}-1.0095 \times \mathrm{TOFF}-0.0706 \times \mathrm{IP}-0.178 \times \mathrm{SV}+0.009 \times \mathrm{TOFF}^{2}+0.00017 \times \mathrm{IP}^{2}+0.0013 \times$ $\mathrm{TOFF} \times \mathrm{IP}+0.004 \times \mathrm{TOFF} \times \mathrm{SV}$

\begin{tabular}{|c|c|c|c|c|c|c|c|}
\hline Sources & $\sum$ squares & $\begin{array}{c}\begin{array}{c}\text { Freedom- } \\
\text { degree }\end{array} \\
\end{array}$ & $\begin{array}{l}\text { Mean- } \\
\text { Square }\end{array}$ & F-value & $P>F$ & Hint & $\%$ Cont \\
\hline Models & 180.930 & 08 & 022.62 & 97.91 & \multirow{6}{*}{$<0.0001$} & \multirow{6}{*}{ Significant } & \\
\hline$A$ & 100.660 & \multirow{5}{*}{1} & 100.66 & 435.74 & & & 52.61 \\
\hline$B$ & 041.270 & & 041.27 & 178.64 & & & 21.57 \\
\hline C & 014.620 & & 014.62 & 63.28 & & & 7.64 \\
\hline$D$ & 009.090 & & 009.09 & 39.35 & & & 4.75 \\
\hline$B^{2}$ & 11.35 & & 11.35 & 49.12 & & & 5.93 \\
\hline
\end{tabular}




\begin{tabular}{|c|c|c|c|c|c|c|c|}
\hline$C^{2}$ & 0.98 & & 0.98 & 4.24 & 0.0453 & & 0.512 \\
\hline$B \times C$ & 2.26 & & 2.26 & 9.77 & 0.0031 & & 1.18 \\
\hline$B \times D$ & 1.59 & 1 & 1.59 & 6.90 & 0.0118 & & 0.83 \\
\hline Residual & 10.39 & 45 & 0.23 & & & & \\
\hline Fit-lack & 9.40 & 40 & 0.24 & 1.18 & 0.4750 & $\begin{array}{c}\text { Not } \\
\text { significant }\end{array}$ & \\
\hline Pure-Error & 0.99 & 5 & 0.20 & & & & \\
\hline $\begin{array}{l}\text { Corrected } \\
\text { Total }\end{array}$ & 191.32 & 53 & & & & & \\
\hline \multicolumn{2}{|c|}{$\begin{array}{c}\text { Standard-Deviation Mean } \\
\text { Coefficient of Variation } \\
\text { PRESS }\end{array}$} & $\begin{array}{c}0.48 \\
6.16 \\
7.80 \\
14.77\end{array}$ & \multicolumn{3}{|c|}{$\begin{array}{c}\mathrm{R}^{2} \\
\text { Adjusted } \mathrm{R}^{2} \text { Predicted } \mathrm{R}^{2} \\
\text { Adequate Precision }\end{array}$} & $\begin{array}{l}0.9457 \\
0.9360 \\
0.9228 \\
40.903\end{array}$ & \\
\hline
\end{tabular}

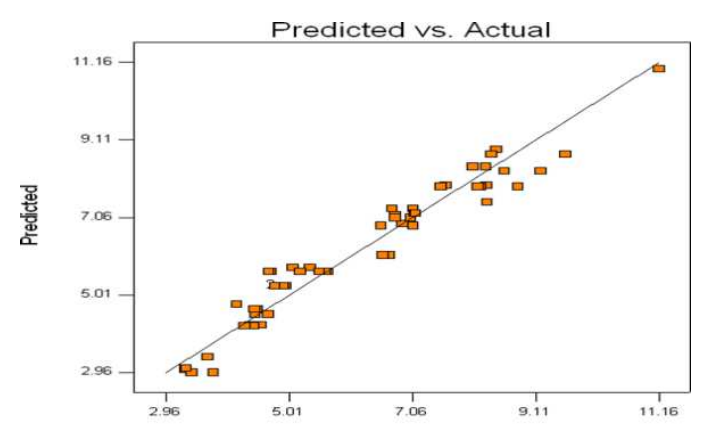

Figure (2.1): Actual-Versus Predicted of MetalRemoval-Rate.

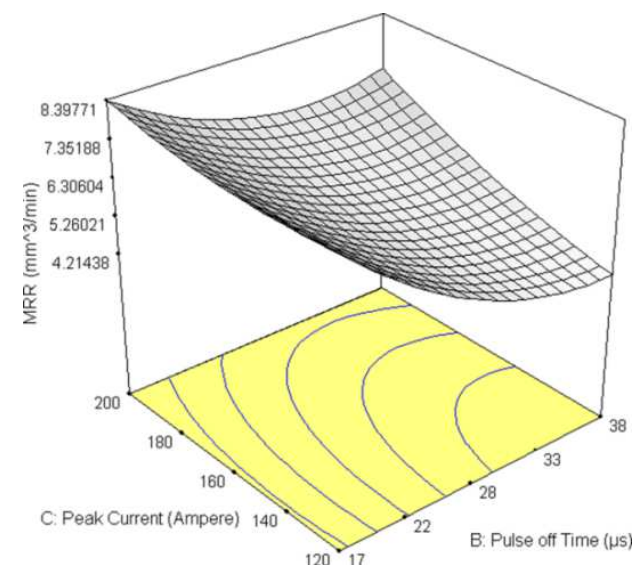

Figure 2.3: Inter-Action Among Pulse off-Time and Peak-Current.

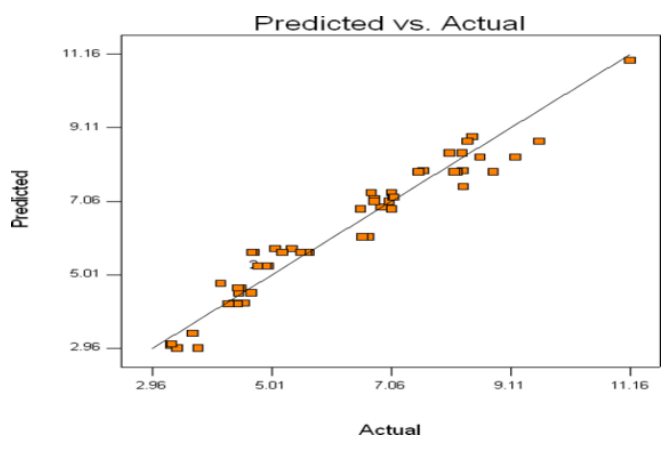

Figure (2.2): Actual Against Predicted of MetalRemoval-Rate.

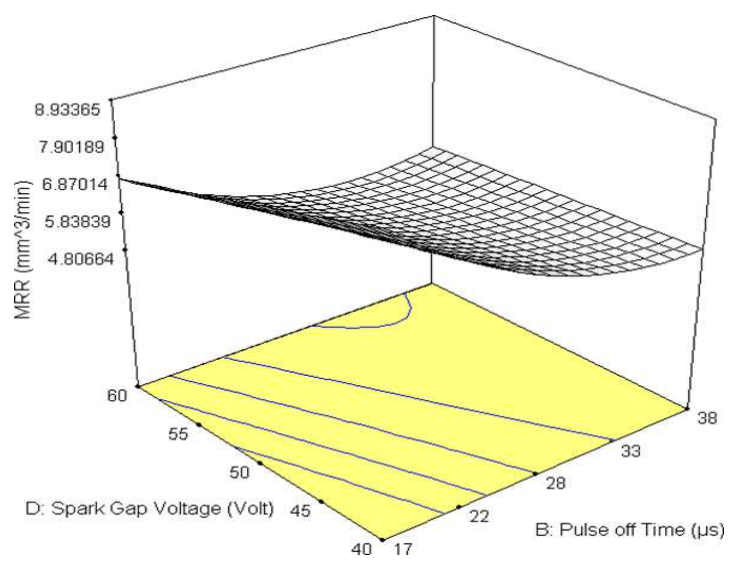

Figure 2.4: Interaction Among Pulse off-Time and Spark-Gap-Voltage.

\section{Surface-Roughness: Analysis of the Model Tools}

The roughness of the surface and its processing is one of the most important criteria for the process. In this process, the state of the surface to be formed is determined. As we have said, this process is the most important of these steps. It should be mentioned that if the surface finish of the work material is the most important and decisive factor, work materials should be classified at low material removal rates. The variance-analysis is given in table (5), during the preparation of the form, in-significant-terms are eliminated by default. Values of "Prob> F" below 0.05 indicate that the formation conditions are important at $95 \%$ confidence level. In addition to this normal piece of residue, the remaining 
residues, as opposed to the forecast, were also drawn as shown in figures(3.1-3.3). Most residue falls on the other-hand straight-line, leading to errors that are distributed in a normal behavior. The results also proves that the regression-model is well-fitted with observed values. The results and charts shows that the expected and observed-values from the analysis is sufficient to determine the real-functional relation among input-parameters and surface-roughness. The model can be recognized as important for which is 145.26 and the p-value which is $<0.05$, moreover, this means that there is $0.01 \%$ chance as the model $\mathrm{F}$ is a large-volume and may have occured due to noise. In MRR-case, there are too factors namely; A \& B contribute nearly $83 \%$ of the total-variation in the response-data. After the surface-equation represents the specific relation among surface-roughness and process-coefficients.

The surface-equation responsible for determining the relation among surface-roughness and process-factors is obtained.

Surface Roughness $3.860-0.767 \times$ TON $-0.035 \times$ TOFF $-0.009 \times$ IP $-0.009 \times \mathrm{SV}+0.1247 \mathrm{WF}-0.0004 \times \mathrm{WT}$ $+0.0003 \times \mathrm{TOFF} 2-0.009 \times \mathrm{WF} 2+0.0000002 \times \mathrm{WT} 2+0.013 \times \mathrm{TON} \times \mathrm{IP}$

Table 5: ANOVA for Response Surface of the Reduced-Quadratic-Model

\begin{tabular}{|c|c|c|c|c|c|c|c|}
\hline Sources & $\sum$ squares & $\begin{array}{l}\text { Freedom- } \\
\text { degree }\end{array}$ & $\begin{array}{l}\text { Mean- } \\
\text { Square }\end{array}$ & F-value & $P>F$ & Hint & $\%$ Cont. \\
\hline Models & 3.08 & 10 & 0.31 & 145.26 & $<0.0001$ & \multirow{9}{*}{ significant } & \\
\hline$A$ & 1.64 & \multirow{8}{*}{1} & 1.64 & 775.10 & $<0.0001$ & & 55.0 \\
\hline$B$ & 0.84 & & 0.84 & 396.22 & $<0.0001$ & & 28.0 \\
\hline$C$ & 0.23 & & 0.23 & 108.54 & $<0.0001$ & & 8.0 \\
\hline$D$ & 0.18 & & 0.18 & 85.03 & $<0.0001$ & & 6.0 \\
\hline$B^{2}$ & 0.013 & & 0.013 & 6.36 & 0.0155 & & 0.41 \\
\hline$E^{2}$ & 0.068 & & 0.068 & 32.18 & $<0.0001$ & & 2.15 \\
\hline$F^{2}$ & 0.019 & & 0.019 & 8.90 & 0.0047 & & 0.6 \\
\hline$A \times F$ & 0.086 & & 0.086 & 40.62 & $<0.0001$ & & 2.71 \\
\hline Residual & 0.091 & 43 & 0.002120 & & & & \\
\hline $\begin{array}{c}\text { Lack of } \\
\text { Fit }\end{array}$ & 0.087 & 38 & 0.002295 & 2.91 & 0.1173 & $\begin{array}{c}\text { Not } \\
\text { Significant }\end{array}$ & \\
\hline Pure Error & 0.003950 & 5 & 0.000790 & & & & \\
\hline \begin{tabular}{|c|} 
Corrected \\
Total
\end{tabular} & 3.17 & 53 & & & & & \\
\hline $\begin{array}{l}\text { Standard } \\
\text { Mean } \\
\text { Coefficient } \\
\text { PRESS }\end{array}$ & $\begin{array}{l}\text { Deviat } \\
\text { of variat }\end{array}$ & $\begin{array}{r}\text { ion0.046 } \\
2.67 \\
\text { ion } 1.73 \\
0.15\end{array}$ & & $\begin{array}{l}\mathrm{R} 2 \\
\text { Adjusted } \\
\text { Predicted } \\
\text { Adequate } \\
\text { Precision }\end{array}$ & $\begin{array}{l}\mathrm{R}^{2} \\
\mathrm{R}^{2}\end{array}$ & $\begin{array}{l}20.9712 \\
20.9646 \\
0.9527 \\
51.529\end{array}$ & \\
\hline
\end{tabular}

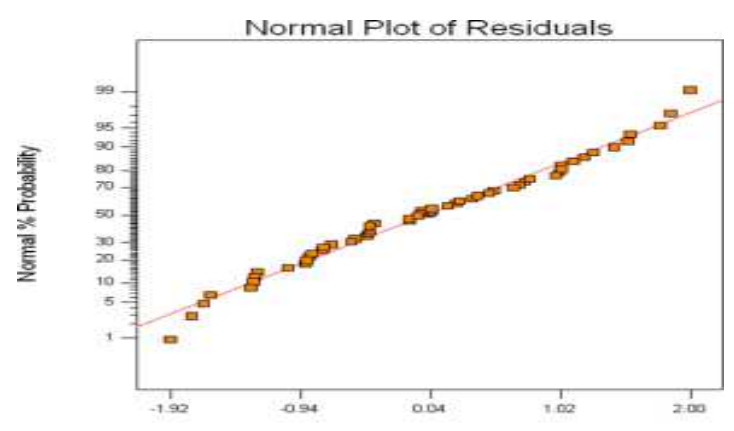

Studentized Residuals

Figure 3.1: Normal-Prob for Residuals of Surface Roughness.

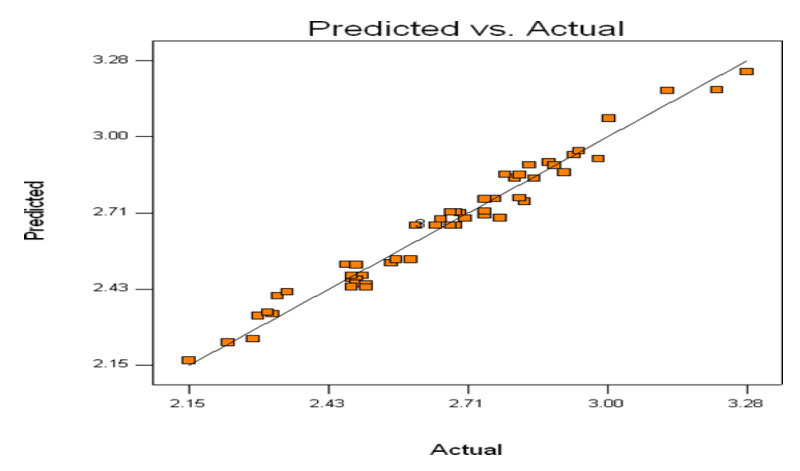

Figure 3.2:Actual Against Predicted of SurfaceRoughness. 


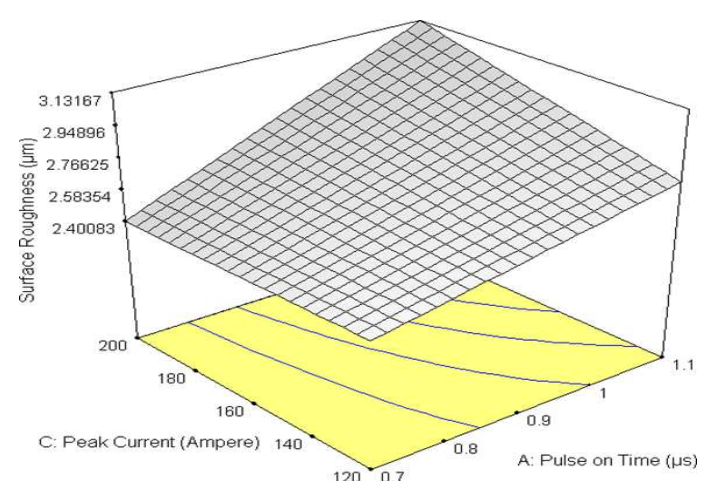

Figure 3.3: Interaction Against on-Time Pulse and Peak-Current.

\section{CONCLUSIONS}

From theoretical and experimental investigation, the following concluded remarks are obtained:

- The parameters of the ideal multi-objective process of responses were verified using final-confirmation experiments and results were found satisfactory.

- The error ratio among predictions of the optimize model and final-confirmation experiments was found to be approximately $4.11 \%$ for MR and nearly $2.99 \%$ for SR.

- The three-dimensional response surfaces and contour-lines showed that pulse on-Time plays a principle role as input-parameters and affects output-responses.

- For MRR \& SR, on the other hand, three-dimensional response surfaces and contour-lines indicated by on Time pulse.

- Off-Time pulse, different results were obtained in different situations because these factors depend on the other hand-position.

\section{REFERENCES}

1. Dinesh, S., Antony, A. G., Rajaguru, K., \& Parameswaran, P. (2018). Comprehensive analysis of wire electric discharge machining process in machining high chromium high carbon steel. International Journal of Mechanical and Production Engineering Research and Development (IJMPERD), 8(1), 65-74.

2. Kumar, A., Kumar, V., \& Kumar, J. (2012). Prediction of Surface Roughness in Wire Electric Discharge Machining (WEDM) Process based on Response Surface Methodology. International Journal of Engineering and Technology, 2(4), 13.

3. Selvakumar, G., BravilinJiju, K., Sarkar, S., \& Mitra, S. (2016). Enhancing die corner accuracy through the trim cut in WEDM. The International Journal of Advanced Manufacturing Technology, 83(5-8), 791-803. https://doi.org/10.1007/s00170-015-7606-0

4. Kumari, R. (2015). Advances in gamma titanium aluminide alloys. Int J Metall Mater Sci Eng, 5(4), 1-8.

5. Prasad Arikatla, S., Tamil Mannan, K., \& Krishnaiah, A. (2017). Parametric Optimization in Wire Electrical Discharge Machining of Titanium Alloy Using Response Surface Methodology. Materials Today: Proceedings, 4(2), 1434-1441. https://doi.org/10.1016/j.matpr.2017.01.165 
6. Azam, M., Jahanzaib, M., Abbasi, J. A., Abbas, M., Wasim, A., \& Hussain, S. (2016). Parametric analysis of recast layer formation in wire-cut EDM of HSLA steel. The International Journal of Advanced Manufacturing Technology, 87(1-4), 713722. https://doi.org/10.1007/s00170-016-8518-3

7. Parashar, V., Rehman, A., Bhagoria, J. L., \&Puri, Y. M. (2010). Kerfs Width Analysis for Wire Cut Electro Discharge Machining of SS 304L Using Design of Experiments. Indian Journal of Science and Technology, 3(4), $369-373$. https://doi.org/10.17485/ijst/2010/v3i4/29719

8. Prabhu, b. D., ramesh, a., \& venkatesh, j. Experimental investigation and analysis of mechanical properties of polyvinyl ester/glass fiber composite with alumina (al2o3), molybdenum disulfide (mos2) and titanium oxide (tio2) fillers.

9. Datta, S., \& Mahapatra, S. S., Modeling, simulation and parametric optimization of the wire EDM process using response surface methodology coupled with grey-Taguchi technique, 22.

10. P. G. Student, M. E (Production) LDRP-ITR, Gandhinagar, Gujarat, Shah, R. A., \& Darji, P. A. (2012). An Experimental Effect of Soft Brass Wire on MRR, Kerf Width and Surface Roughness of AISI D2 Tool Steel in WEDM. Global Journal for Research Analysis, 3(5), 1-3. https://doi.org/10.15373/22778160/MAY2014/64

11. Subrahmanyam, S. V., \& Sarcar, M. M. M. (2013). Application of Machine Learning Techniques in the Process Modeling of WEDM, 3(12), 7.

12. Shah, A., Mufti, N. A., Rakwal, D., \& Bamberg, E. (2011). Material Removal Rate, Kerf, and Surface Roughness of Tungsten Carbide Machined with Wire Electrical Discharge Machining. Journal of Materials Engineering and Performance, 20(1), 7176. https://doi.org/10.1007/s11665-010-9644-y 